\title{
ANALISIS KECEPATAN ARUS AIR MENGGUNAKAN CURRENT METER DAN KARAKTERISTIK SUNGAI TUAN HAJI BESAR MUHAMMAD ARSYAD AL BANJARI KABUPATEN BANJAR
}

\author{
Adhi Surya ${ }^{1}$ dan Budi Setiawan ${ }^{2}$ \\ ${ }^{1}$ Staf Pengajar Program Studi Teknik Sipil, Fakultas Teknik, \\ Universitas Islam Kalimantan Muhammad Arsyad Al Banjari \\ ${ }^{2}$ Mahasiswa Program Studi Teknik Sipil, Fakultas Teknik, \\ Universitas Islam Kalimantan Muhammad Arsyad Al Banjari \\ E-mail: adhisuryastmt@gmail.com/HP.0877.8273.8533
}

\begin{abstract}
ABSTRAK
Penelitian ini menganalisis kecepatan arus air Sungai Tuan dan mengidentifikasi karakteristik Sungai Tuan Haji Besar Muhammad Arsyad Al Banjari. Dalam pelaksanaannya menggunakan Alat Current Meter tipe "Flowatch FL-03" sistem yang dirancang ini dapat digunakan untuk menghitung kecepatan arus air pada Sungai Tuan yang memiliki pola arus mendatar (stream line). Tata cara pelaksanaan menggunakan panduan dari SNI 3408-2015 dan beberapa jurnal pendukung lainnya. Pengukuran kecepatan arus air sungai dilakukan sangat berpengaruh bagi sistem irigasi untuk mengairi persawahan serta akibat perubahan-perubahan karakteristik sungai disepanjang sungai tuan yang sekarang ini sangat kritis. Seiring semakin meningkatnya pertumbuhan penduduk mengakibatkan kondisi Sungai Tuan Kecamatan Astambul mengalami penurunan dengan menyusutnya daerah resapan air yang menjadikan kondisi tanah yang telah jenuh air dan tertutupnya saluran air oleh padatnya bangunan, dan juga banyak sungai maupun bantaran sungai yang mengalami perubahan fisik sungai (penyempitan, pendangkalan, erosi, dan penutupan mulut sungai).
\end{abstract}

Kata kunci : Pengukur Kecepatan, Sruktur dan Lingkungan, Sedimen, Pengaruh Debit, Sedimen dan Laju Sedimen, Permukiman Kumuh.

\begin{abstract}
This study analyzes the velocity of the Tuan River's water flow and identifies the characteristics of the Tuan Haji Besar Muhammad Arsyad Al Banjari River. In its implementation, using a Current Meter Tool type "Flowatch FL-03" this designed system can be used to calculate the speed of water flow in the Tuan River which has a stream line pattern. The implementation procedure uses guidelines from SNI 34082015 and several other supporting journals. Measurement of the speed of river water flow is very influential for the irrigation system to irrigate rice fields and due to changes in river characteristics along the Tuan River which are currently very critical. Along with increasing population growth, the condition of the Tuan River in Astambul District has decreased with the shrinking of the water catchment area which has made the soil condition saturated with water and closed waterways by dense buildings, and also many rivers and riverbanks have experienced physical changes in the river (narrowing, silting). , erosion, and river mouth closure).
\end{abstract}


Keywords : Velocity Measurement, Structure and Environment, Sediment, Discharge Effect, Sediment and Sediment Rate, Slum Settlement.

\section{PENDAHULUAN}

Penelitian ini merupakan lanjutan dari penelitian Adhi Surya, ST., MT dan Dewi Ariefahnoor, SE., MM yang berjudul Haritage Sungai Tuan yang berfungsi teknis sebagai karya teknis Syekh Muhammad Arsyad Al Banjari dari Perspektif Teknik Sipil (2018). Sungai Tuan yang terletak di Kecamatan Astambul dengan panjang sungai $8 \mathrm{Km}$. Pada saat sekarang ini aliran di daerah Sungai Tuan terdapat beberapa hambatan dibantaran sungai dan disungai tersebut seperti tumbuhan rumput liar, pohon-pohon keras, bangunan rumah yang tidak beraturan, limbah rumah tangga dan limbah perkebunan yang mengakibatkan terganggunya sistem aliran air. Hal ini jelas berdampak pada kecepatan aliran dan perubahan-perubahan karakteristik sungai itu sendiri. Oleh karena itu perlu dilakukan studi penelitian untuk mengetahui kecepatan aliran dan mengidentifikasi karakteristik Sungai Tuan. Skripsi ini penulis dalam pelaksanaan penelitian digunakan alat ukur kecepatan aliran air sungai yaitu Current Meter dengan metode SNI 3408-2015 dan jurnal pendukung lainnya. Alat Current Meter tipe Flowatch FL-03 menghitung kecepatan m/dtk secara otomatis. Alat tersebut memiliki kepekaan terhadap aliran air sehingga dapat mendapatkan hasil yang lebih detail.

\section{TINJAUAN PUSTAKA}

Sungai Tuan yang terletak Km. 55,500 dari Kota Banjarmasin, Kabupaten Banjar di Kecamatan Astambul. Sepanjang Sungai Tuan bermukim penduduk yang dibagi berberapa Desa yaitu Desa Sungai Tuan Ulu, Desa Sungai Tuan Ilir, Desa Banua Anyar Sungai Tuan, Desa Kelampaian Ilir, Desa Astambul Kota dan Desa Tambangan. Data yang diperoleh dari Kecamatan Astambul tercatat 2.580 Kepala Keluarga. Sungai Tuan sebagai salah satu sumber daya alam yang sangat penting, di satu pihak mempunyai banyak manfaat, namun di lain pihak juga dapat menimbulkan ancaman bagi kehidupan dan penghidupan manusia.

Erosi dan sedimentasi merupakan dua buah masalah yang saling berkaitan. Erosi tanah yang meliputi proses pelepasan butir-butir tanah dan proses pemindahan tanah akan menyebabkan timbulnya bahan endapan atau sedimentasi di tempat lain. Pada saat permulaan turun hujan, pukulan jatuhnya air hujan merupakan penghasil utama butir-butir yang terlepas dalam proses erosi tanah. Bersama dengan aliran air,butir-butir tanah yang lepas akibat proses erosi akan diangkut masuk ke dalam aliran sungai dan kemudian akan diendapkan pada tempat-tempat tertentu (pada muara sungai dan waduk) berupa pengendapan atau sedimentasi. Endapan sedimen tersebut apabila semakin lama semakin terakumulasi jumlahnya, maka akan menimbulkan pendangkalan pada waduk dan muara sungai yang selanjutnya akan berakibat terhadap berkurangnya umur rencana waduk. Banyaknya angkutan bahan endapan tergantung dari besarnya erosi tanah yang terjadi. Semakin banyak jumlah bahan sedimen yang terangkut menunjukkan makin besar tingkat erosi tanah yang terjadi dalam daerah aliran sungai yang bersangkutan. 
JURNAL KACAPURI

JURNAL KEILMUAN TEKNIK SIPIL

Volume 4 Nomor 2 Edisi Desember 2021

\section{METODOLOGI PENELITIAN}

Lokasi penelitian pada Sungai Tuan Besar Syekh Muhammad Arsyad Al Banjari, bertempat dilokasi Kecamatan Astambul, Kabupaten Martapura yang berjarak Km. 55,500 dari Kota Banjarmasin.
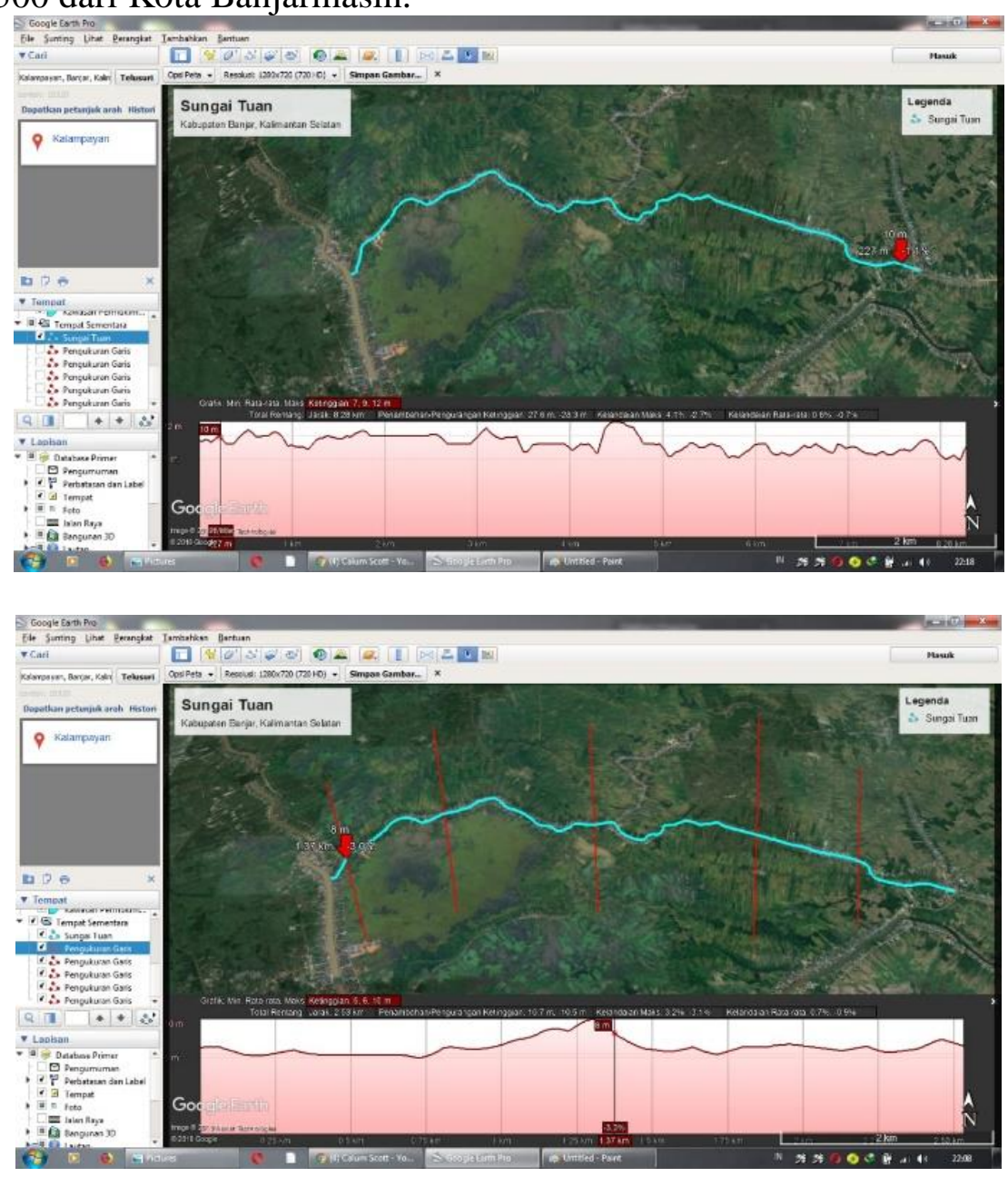

Gambar 1. Peta Lokasi Sungai Tuan

\section{Metode Current Meter}

1. Ukur lebar air yang akan dilakukan pengukuran oleh current meter, kemudian bagi menjadi tiga bagian yaitu sisi bagian kiri, bagian tengah dan sisi bagian kanan.

2. Ukur kedalaman air dan tentukan titik-titik kedalaman yang akan diukur kecepatannya.

3. Setelah diketahui kedalaman air, pengukuran pada berbagai kedalaman sesuai dengan daftar berikut: 
Tabel 1. Pengukuran pada berbagai kedalaman

\begin{tabular}{cll}
\hline $\begin{array}{c}\text { Kedalaman } \\
\text { Sungai }(\mathrm{m})\end{array}$ & Kedalaman Pengukuran & Perhitungan kecepatan Rata-Rata \\
\hline $0-0.6$ & $0.6 \mathrm{~h}$ & $\mathrm{~V}=\mathrm{V} 0.6$ \\
$0,6-3,0$ & $0.2 \mathrm{~h}$ dan $0.8 \mathrm{~h}$ & $\mathrm{~V}=0.5(\mathrm{~V} 0.2+\mathrm{V} 0.8)$ \\
$3,0-6,0$ & $0.2 \mathrm{~h}, 0.6 \mathrm{~h}$ dan $0.8 \mathrm{~h}$ & $\mathrm{~V}=0.25(\mathrm{~V} 02+\mathrm{V} 0.6+\mathrm{V} 0.8)$ \\
$>6,0$ & $0.2 \mathrm{~h}, 0.6 \mathrm{~h}, 0.8 \mathrm{~h}$ dan $\mathrm{b}$ & $\mathrm{V}=0.1(\mathrm{Vs}+3 \mathrm{~V} 0.2+3 \mathrm{~V} 0.6+3 \mathrm{~V} 0.8+\mathrm{Vb})$ \\
\hline
\end{tabular}

\section{HASIL DAN PEMBAHASAN}

\section{Hasil dan Pembahasan pengukuran Current Meter di Sungai Tuan}

Hasil pengukuran kecepatan arus air di sungai Tuan Haji Besar Muhammad Arsyad Al Banjari di Station Awal sebagai berikut:

Tabel 2. Hasil pengukuran kecepatan arus air menggunakan Current Meter di Station Awal

\begin{tabular}{|c|c|c|c|c|c|c|c|c|c|}
\hline \multirow{2}{*}{$\begin{array}{c}\text { No. } \\
\text { Profil }\end{array}$} & \multirow[b]{2}{*}{$\begin{array}{c}\mathrm{h} \\
(\mathrm{m}) \\
\end{array}$} & \multicolumn{3}{|c|}{$\begin{array}{l}\text { Pembacaan } 10 \\
\text { detik }\end{array}$} & \multirow{2}{*}{$\mathrm{m} / \mathrm{dtk}$} & \multirow[b]{2}{*}{$\begin{array}{c}\text { I } \\
(\mathrm{m})\end{array}$} & \multirow[b]{2}{*}{$\begin{array}{c}\mathrm{H} \\
(\mathrm{m})\end{array}$} & \multirow{2}{*}{$\begin{array}{c}\text { Lebar } \\
\text { Muka } \\
\text { Air } \\
\text { (m) }\end{array}$} & \multirow[b]{2}{*}{$\begin{array}{c}\text { Sudut } \\
\left(0^{\circ}\right)\end{array}$} \\
\hline & & I & II & III & & & & & \\
\hline $\begin{array}{c}\text { Sta. } \\
\text { Akhir } \\
\text { h1 }\end{array}$ & 0,6 & 0,03 & 0,02 & 0,03 & 0,06 & 1,00 & 0,68 & 5,00 & $90^{\circ}$ \\
\hline \multirow[t]{2}{*}{ h2 } & 0,2 & 0 & 0 & 0 & 0 & 2,43 & 1,10 & & $90^{\circ}$ \\
\hline & 0,8 & 0,03 & 0,03 & 0,03 & 0,07 & & & & $90^{\circ}$ \\
\hline h3 & 0,6 & 0,03 & 0,02 & 0,03 & 0,06 & 1,57 & 0,73 & & $90^{\circ}$ \\
\hline
\end{tabular}

Sumber: Hasil Penelitian

Potongan melintang Sungai Tuan di Station Awal

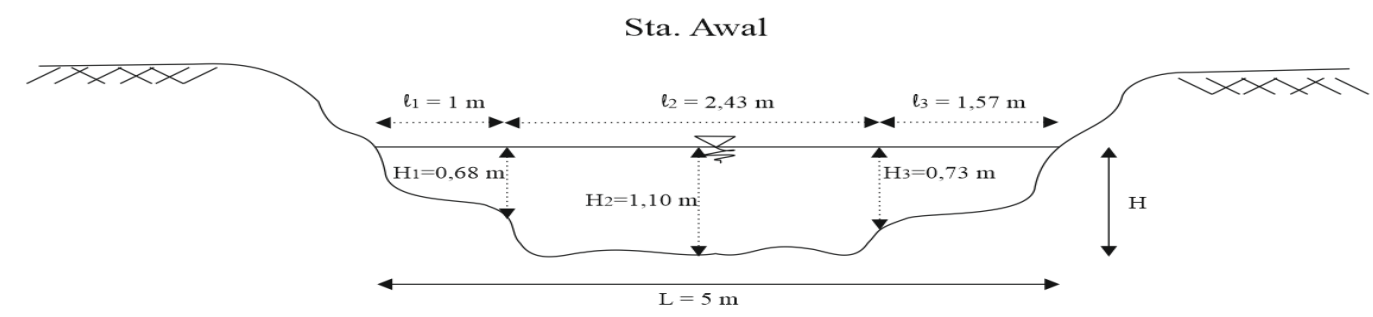

Gambar 3. Profil Potongan Melintang Sungai Tuan di Station Awal 
Perhitungan kecepatan aliran di Station Awal

Kecepatan aliran sungai (V) di Sta. Awal

- Kecepatan V1 di kedalaman 0,6 m

$\mathrm{V}$ rata-rata $=\mathrm{V}_{0,6 \mathrm{H}}$

$\mathrm{V}$ rata-rata $=0,06 \mathrm{~m} / \mathrm{dtk}$

- Kecepatan V2 di kedalaman 0,2 m dan 0,8 m

$\begin{aligned} & \mathrm{V} \text { rata-rata }=\frac{\mathrm{V}_{0,2 \mathrm{H}}+\mathrm{V}_{0,8 \mathrm{H}}}{2} \\ & \begin{aligned} \mathrm{V} \text { rata-rata } & =\frac{0+0,7}{2} \\ & =0,35 \mathrm{~m} / \mathrm{dtk}\end{aligned}\end{aligned}$

- Kecepatan V3 di kedalaman 0,6 m

$\mathrm{V}$ rata-rata $=\mathrm{V} 0,6 \mathrm{H}$

$\mathrm{V}$ rata-rata $=0,06 \mathrm{~m} / \mathrm{dtk}$

Kecepatan aliran Sungai Sta. Awal

$\mathrm{V}$ aliran $=\frac{\mathrm{V} 1+\mathrm{V} 2+\mathrm{V} 3}{3}$

$$
\begin{aligned}
& =\frac{0,06+0,35+0,06}{3} \\
& =0,16 \mathrm{~m} / \mathrm{dtk}
\end{aligned}
$$

Jadi, Kecepatan di Sta. Awal adalah: 0,16 m/dtk

Hasil pengukuran kecepatan arus air di sungai Tuan Haji Besar Muhammad Arsyad Al Banjari di Station Akhir sebagai berikut:

Tabel 3 Hasil pengukuran kecepatan arus air menggunakan Current Meter di

\begin{tabular}{|c|c|c|c|c|c|c|c|c|c|}
\hline \multirow{2}{*}{$\begin{array}{l}\text { No. } \\
\text { Profil }\end{array}$} & \multirow[b]{2}{*}{$\begin{array}{c}\mathrm{h} \\
(\mathrm{m})\end{array}$} & \multicolumn{3}{|c|}{$\begin{array}{l}\text { Pembacaan } 10 \\
\text { detik }\end{array}$} & \multirow{2}{*}{$\mathrm{m} / \mathrm{dtk}$} & \multirow[b]{2}{*}{$\begin{array}{c}\text { I } \\
(\mathrm{m})\end{array}$} & \multirow[b]{2}{*}{$\begin{array}{c}\mathrm{H} \\
(\mathrm{m})\end{array}$} & \multirow{2}{*}{$\begin{array}{c}\text { Lebar } \\
\text { Muka } \\
\text { Air } \\
(\mathrm{m})\end{array}$} & \multirow[b]{2}{*}{$\begin{array}{l}\text { Sudut } \\
\left(0^{\circ}\right)\end{array}$} \\
\hline & & I & II & III & & & & & \\
\hline $\begin{array}{l}\text { Sta. } \\
\text { Akhir } \\
\text { h1 }\end{array}$ & 0,6 & 0,25 & 0,23 & 0,23 & 0,56 & 1,05 & 0,77 & 9,00 & $90 \circ$ \\
\hline h2 & 0,2 & 0,28 & 0,23 & 0,25 & 0,59 & 6,80 & 1,68 & & $90^{\circ}$ \\
\hline & 0,8 & 0,34 & 0,28 & 0,28 & 0,71 & & & & $90^{\circ}$ \\
\hline h3 & 0,6 & 0,24 & 0,22 & 0,23 & 0,54 & 1,15 & 0,47 & & $90 \circ$ \\
\hline
\end{tabular}
Station Akhir

Sumber: Hasil Penelitian 
Potongan melintang Sungai Tuan di station akhir

Sta. Akhir

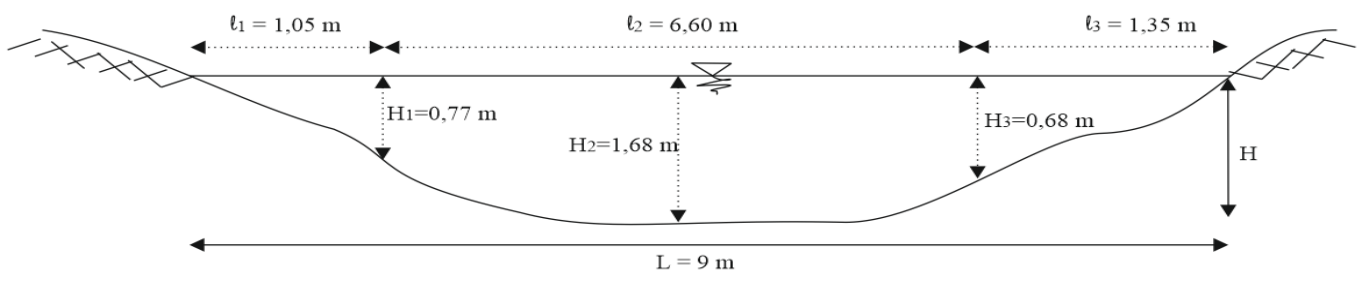

Gambar 4. Profil Potongan Melintang Sungai Tuan di Station Akhir Perhitungan kecepatan aliran di station akhir

Kecepatan aliran sungai (V) di Sta. Akhir

- Kecepatan V1 di kedalaman 0,6 m

$\mathrm{V}$ rata-rata $=\mathrm{V}_{0,6 \mathrm{H}}$

$\mathrm{V}$ rata-rata $=0,56 \mathrm{~m} / \mathrm{dtk}$

- Kecepatan V2 di kedalaman 0,2 m dan 0,8 m

$\mathrm{V}$ rata-rata $=\frac{{\mathrm{V} 0,2 \mathrm{H}+\mathrm{V}_{0,8 \mathrm{H}}}_{2}}{0.59+0.71}$

$\mathrm{V}$ rata-rata $=\frac{0,59+0,71}{2}$

$=0,65 \mathrm{~m} / \mathrm{dtk}$

- Kecepatan V3 di kedalaman 0,6 m

$\mathrm{V}$ rata-rata $=\mathrm{V}_{0,6 \mathrm{H}}$

$\mathrm{V}$ rata-rata $=0,54 \mathrm{~m} / \mathrm{dtk}$

Kecepatan aliran Sungai Sta. Akhir

$$
\begin{aligned}
\mathrm{V} \text { aliran } & =\frac{\mathrm{V} 1+\mathrm{V} 2+\mathrm{V} 3}{3} \\
& =\frac{0,56+0,65+0,54}{3} \\
& =0,58 \mathrm{~m} / \mathrm{dtk}
\end{aligned}
$$

Jadi, Kecepatan di Sta. Akhir adalah: 0,58 m/dtk

\section{Hasil dan Pembahasan pengukuran Karakteristik Sungai Tuan}

Potongan penampang melintang Sungai Tuan di Station Awal dan Akhir

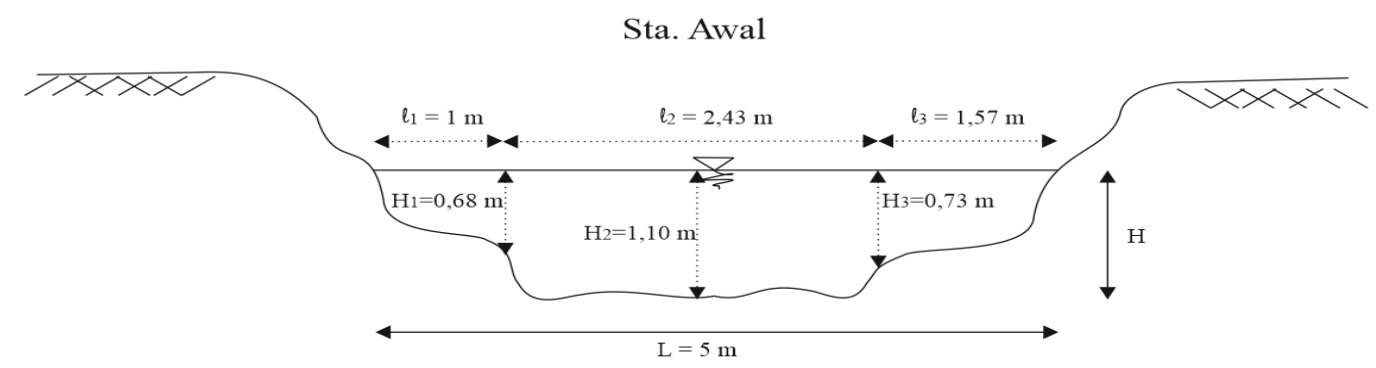

Gambar 5. Profil Potongan Melintang Sungai Tuan di Station Awal 


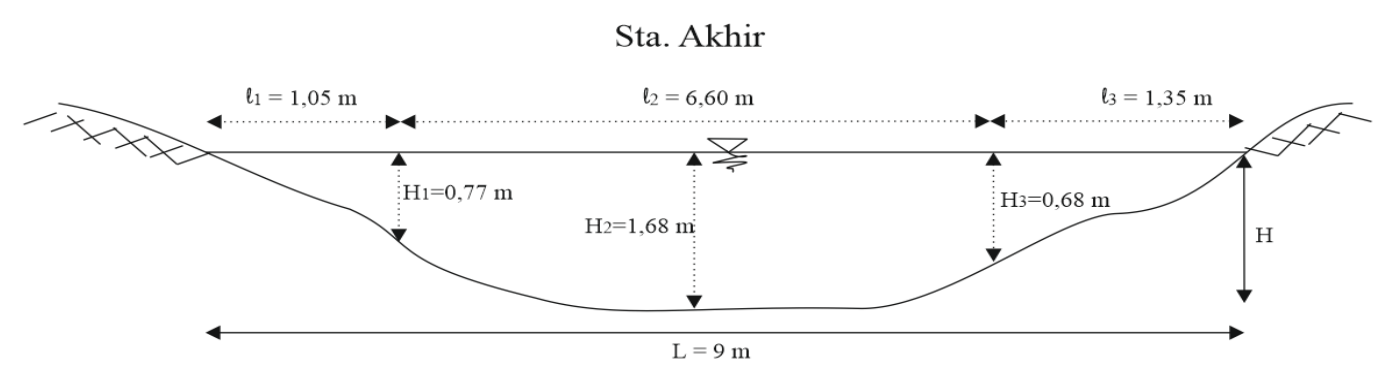

Gambar 6. Profil Potongan Melintang Sungai Tuan di Station Akhir

Hasil pengukuran penampang melintang Sungai Tuan

Pengukuran di Station Awal:

Lebar Sungai (L) : 5 meter

Kedalaman sungai $(\mathrm{h})$

$\begin{array}{lll}\text { - } & \text { Kiri } & : 0,68 \text { meter } \\ \text { - } & \text { Tengah } & : 1,10 \text { meter } \\ \text { - } & \text { Kanan } & : 0,73 \text { meter }\end{array}$

Pengukuran di Station Akhir:

Lebar Sungai (L) : 9 meter

Kedalaman sungai (h)

- Kiri $\quad: 0,77$ meter

- Tengah : : 1,68 meter

- Kanan : 0,68 meter

\section{Pembahasan Karakteristik Sungai Tuan}

Perubahan sejarah karakteristik sungai tuan sepanjang $8 \mathrm{~km}$ mengalami perubahan bentuk tampang aliran yang menyangkut kondisi fisik sungai tentang geometri, jenis, sifat, dan prilaku sungai dengan segala aspek perubahannya dalam dimensi ruang waktu. Karakteristik sungai dapat dipengaruhi oleh berbagai faktor di antaranya kondisi aliran, proses angkutan sedimen, kondisi lingkungan, serta aktivitas manusia disekitarnya.

Kondisi sungai tuan sekarang ini mengalami perubahan penyempitan dan pendangkalan yang hanya dengan lebar 3-9 meter dan kedalaman $2-3$ meter yang diakibatkan proses sedimentasi dengan adanya daratan, tanaman liar serta pohonpohon keras, dan banyaknya bangunan rumah disepanjang aliran sungai tuan.

Faktor-faktor penyebab perubahan karakteristik di Sungai Tuan

- Pendangkalan dan penyempitan sungai akibat sedimentasi erosi, lumpur, dan sampah. Sedimentasi ini mengandalkan kekuatan aliran air. Ketika aliran air deras atau kuat, material akan cepat terangkut, namun jika lemah maka material akan terendapkan di dasar sungai.

- Membangun rumah diatas sungai atau dibantaran sungai dapat menyebabkan penyempitan badan sungai sehingga aliran air akan terhambat, akibatnya akan terjadi banjir, tercemarnya kualitas air disungai akibat limbah rumah tangga dan industri, terjadinya pengendapan disekitar bangunan tersebut yang menyebabkan terhalangnya aliran air sungai 
- Tumbuh suburnya rumput-rumput dan pohon-pohon keras dibantaran sungai mengakibatkan berkurangnya kapasitas aliran air sungai.

- Budaya, masyarakat yang terbiasa membuang sampah disungai yang terdiri dari sampai organik, anorganik, sampah basah, dan kering sehingga menyebabkan air tercemar baik dari warna, bau dan rasa.

- Sumber daya tanah, pada daerah aliran sungai masih terjadi erosi dalam skala kecil. Tanahnya cukup subur, namun keberadaan tanah ini sering tercemari oleh sampah-sampah dan limbah buangan rumah tangga yang berwujud cair, yang akibatnya membuat bau dan mencemari tanah.

Upaya-upaya yang dapat dilakukan dalam menangani permasalahan pada Sungai Tuan adalah:

- Pengerukan pada sedimentasi tanah pada Sungai secara berkala.

- Pencegahan pendirian bangunan liar disepanjang Sungai Tuan.

- Pembersihan tanaman rumput dan pohon liar yang tumbuh mengganggu aliran Sungai Tuan.

- Pencegahan dan penyadaran masyarakat sekitar agar tidak membuang sampah ke Sungai.

- Pencegahan erosi perlu adanya penghijauan dengan tanaman keras dan pembangunan dinding penahan tanah pada beberapa lokasi yang rawan longsor.

\section{Kesimpulan}

\section{PENUTUP}

Dari hasil studi kecepatan aliran air dan karakteristik pada Sungai Tuan Haji Besar Syekh Muhammad Arsyad Al Banjari dapat disimpulkan sebagai berikut:

1. Analisis kecepatan arus air menggunakan Current Meter, yaitu:

a. Pengukuran kecepatan aliran dititik Awal yang menggunakan alat Current Meter, perhitugan dibagi menjadi tiga titik dengan jarak berbeda per titik yaitu $\mathrm{h}_{1}, \mathrm{~h}_{2}$ dan $\mathrm{h}_{3}$, masing masing memiliki kecepatan aliran tersendiri, kecepatan aliran minimun $0 \mathrm{~m} / \mathrm{dtk}$, kecepatan aliran maksimum $0.7 \mathrm{~m} / \mathrm{dtk}$ dan rata-rata keseluruhan adalah $0.16 \mathrm{~m} / \mathrm{dtk}$.

b. Pengukuran kecepatan aliran dititik Akhir yang menggunakan alat Current Meter, perhitugan dibagi menjadi tiga titik dengan jarak berbeda per titik yaitu $\mathrm{h}_{1}, \mathrm{~h}_{2}$ dan $\mathrm{h}_{3}$, masing masing memiliki kecepatan aliran tersendiri, kecepatan aliran minimun $0.23 \mathrm{~m} / \mathrm{dtk}$, kecepatan aliran maksimum $0.28 \mathrm{~m} / \mathrm{dtk}$ dan ratarata keseluruhan adalah $0.58 \mathrm{~m} / \mathrm{dtk}$.

2. Karakteristik Sungai Tuan Haji Besar Muhammad Arsyad Al Banjari, yaitu: Selama pengamatan di sepanjang Sungai Tuan memiliki karakteristik bermacammacam seperti:

a. Sedimentasi mengakibatkan Pendangkalan dan penyempitan Sungai Tuan.

b. Pembangunan rumah penduduk diatas atau bantaran Sungai Tuan.

c. Tanaman liar dan pohon keras yang tumbuh subur dibantaran Sungai Tuan.

d. Kurangnya kesadaran dan kepedulian masyarakat untuk tidak membuang sampah di Sungai Tuan.

e. Penurunan dinding Sungai Tuan dan lonsor diakibatkannya erosi. 


\section{Saran}

1. Analisa kecepatan arus air menggunakan Current Meter didapat data pengukuran kecepatan aliran bisa digunakan pada penelitian tingkat lanjut untuk dapat melakukan berbagai proyek di Sungai Tuan karena masih perlunya perhatian Pemerintah Daerah untuk pemanfaatan Sungai Tuan.

2. Karakteristik Sungai Tuan dengan hasil pengukuran dan foto-foto dilapangan. Pemerintah Daerah diharapkan bisa menormalisasi Sungai Tuan berfungsi normal, sehingga bisa membantu masyarakat dibidang pertanian dan tranportasi air karena sudah dalam keadaan kritis.

3. Pengukuran kecepatan arus air dilakukan selama 24 jam dilokasi yang sama dan titik pengukuran yang sama.

4. Pengukuran penampang Sungai dan panjang effektif Sungai Tuan dengan menggunakan perahu.

\section{DAFTAR PUSTAKA}

(BSN) Badan Standarisasi Nasional. 2015. SNI 3408 : 2015, Tata cara pengukuran kecepatan aliran pada uji model hidraulik fisik (UMH-Fisik) dengan alat ukur arus tipe baling-baling : Jakarta.

Badan Pusat Statistik Kabupaten Banjar. 2020. Statistik Daerah Kecamatan Astambul 2020. Kabupaten Banjar.

Christiany, Ari., Wahyudi, Wawan., Satria Irfan., Nugraha, P, Ardi. 2016. "Pengelolaan Sumber Daya Alam dan Lingkungan". Program Studi Pengelolaan Sumber daya Alam Institut Pertanian Bogor : Bogor.

Fasdarsyah. 2016. Analisis Karakteristik Sedimen Dasar Sungai Terhadap Parameter Kedalaman. Program Studi Teknik Sipil Universitas Malikussaleh : Aceh.

Hambali, Roby., dan Apriyanti, Yayuk. 2016. Studi Karakteristik Sedimen Dan Laju Sedimentasi Sungai Daeng - Kabupaten Bangka Barat. Jurusan Teknik Sipil Fakultas Teknik Universitas Bangka Belitung Kampu Terpadu UBB Balunijuk, Merawang, Kab. Bangka.

Hakki, Wan ${ }^{1}$., Sugiyanta, I Gede ${ }^{2}$., Haryono, Edy ${ }^{3}$. 2015. Dampak Pemanfaatan Bantaran Sungai Terhadap Kualitas Lingkungan Di Kelurahan Pasar Krui. Program Studi Pendidikan Geografi Jurusan Pendidikan Ilmu Pengetahuan Sosial Fakultas Keguruan Dan Ilmu Kependidikan Universitas Lampung.

Norhadi, Ahmad (1)., Marzuki, Akhmad ${ }^{(1)}$., Wicaksono, Luki (1)., Yacob, Addetya, Rendi ${ }^{(2)}$. 2015. Studi Debit Aliran Pada Sungai Antasan Kelurahan sungai Andai Banjarmasin Utara. ${ }^{(1)}$ Staf Pengajar Jurusan Teknik Sipil Politeknik Negeri Banjarmasin ${ }^{(2)}$ Mahasiswa Jurusan Teknik Sipil Politeknik Negeri Banjarmasin

Teknik, Kampus. 2020. Cara Cepat Menghitung Debit Aliran Sungai Menggunakan Current Meter. Available online at: https://www.youtube.com/watch?v= WT91x0TLvZY (diakses 8 Juni 2020) 
Surya,Adhi, ST, MT dan Ariefahnoor, Dewi, SE, MM. 2018. Heritage Sungai Tuan Yang Berfungsi Teknis Sebagai Karya Teknis Syekh Muhammad Arsyad Al Banjari Dari Perspektif Teknik Sipil. Laporan Akhir. Penelitian Dosen, Universitas Islam Kalimantan selatan Muhammad Arsyad Al Banjari: Banjarmasin.

Prof. Dr. Ir. Ishak, M. Galib, MS., Dr. Herman, Rudi, ST., M.Sc. 2020. Rekayasa Sungai. Untad Press.

Pandeirot, Anggraini F. M., Rombang, Johan A., Saroinsong ,Fabiola B ${ }^{(1)}$. 2017. Kapasistas Saluran Sungai Karombasan. ${ }^{(1)}$ Program Studi Ilmu Kehutanan, Jurusan Budidaya Pertanian, Fakultas Pertanian, Universitas Sam Ratulangi, Manado.

Parlina, Iin. 2020. Pengukuran Debit Aliran Sungai Dengan Menggunakan Laju Terukur Dan Geometri Aliran. Pusat Teknologi Lingkungan, Gd.Geostech 820, BPPT, Kawasan Puspiptek, Tangerang Selatan, 15314, Indonesia.

Surbakti, Heron. 2012. Karakteristik Pasang Surut dan Pola Arus di Muara Sungai Musi, Sumatera Selatan. Program Studi Ilmu Kelautan, Universitas Sriwijaya: Sumatera Selatan.

Usman, Kurnia Oktavia. 2014. Analisis Sedimentasi Pada Muara Sungai Komering Kota Palembang. Program Studi Teknik Sipil Universitas Sriwijaya: Sumatera Selatan

Zulfahmi ${ }^{1}$., Syam AS, Nur ${ }^{2}$., Jufriadi ${ }^{3}$. 2016. Dampak Sedimentasi Sungai Tallo Terhadap Kerawanan Banjir Di Kota Makassar. 1,2 Teknik Perencanaan Wilayah dan Kota, Fakultas Sains dan Teknologi, Universitas Islam Negeri Alauddin Makassar ${ }^{3}$ Teknik Perencanaan Wilayah dan Kota, Fakultas Teknik, Universitas Bosowa 45 Makassar. 